\title{
Performative Discourse of Drag QueEns: A SOCIOLINGUISTIC STUDY
}

\author{
MARIA SZYMAŃSKA \\ University of Lodz, Poland \\ maria.szymanska@uni.lodz.pl
}

\begin{abstract}
The article presents the analysis of two speeches given by Rory O'Neill, also known as Panti Bliss, who is so far the most recognisable Irish drag queen. Apart from being a drag queen, Rory O'Neill is also a political activist whose performances were part of the campaign before the referendum concerning the 34th Amendment to the Constitution of Ireland. In the analysis both these aspects of the speaker's identity are taken into consideration. Although the analysis is mostly linguistic, it also considers extralinguistic aspects of communication, e.g. the performer's appearance on stage, as contextual elements are essential in sociolinguistic contexts. Thus, the analysis draws from the theoretical background focused on political discourse and the language used by drag queens to a detailed account of the two speeches in order discuss them in relation to the standards of both a drag performance and a political speech.
\end{abstract}

Keywords: drag queens, discourse, political discourse, language and identity

\section{Drag - an introduction}

Giving the definition of drag can be as controversial as the phenomenon itself. There is no general agreement among performers, but also much confusion among the researchers, about who can do drag and what the role of drag performances is. Researchers who have attempted to give a definition for a term drag queen (e.g. Barrett 1998, 1999, 2017; Fleisher 1996; Greaf 2016; Rupp et al. 2010) have also presented different interpretations of drag performances. Some see a drag performance as an intrinsically misogynistic act, a mockery of women (Ackroyd 1979; Garber 1983; Raymond 1994, 1996; Williamson 1986), others perceive it primarily as a way through which a performer reinforces his masculinity by adapting the feminine qualities without biologically being a woman (Gilbert 1980; Showalter 1983). On the other hand, there are feminist scholars who negate the claim that the phenomenon is a mockery of women, emphasising the fact that drag is not strictly about women, but about the social roles assigned to sexes by society (e.g. Butler 1990, 1993; Feinberg 1996; Hilbert 1995). For Butler (1990) drag is 
a perfect illustration of the performative nature of gender. She praises drag for disconnecting the concepts of masculinity and femininity from the assigned sex (Butler 1990). The role assigned to drag by queer theorists, which has a profoundly political force aiming to discredit gender-related assumptions, is often not the goal of the artists themselves who, through drag, want to express their own identity. However, Barrett (2017) sees such interpretations of drag as "exploiting drag queen identity for the sake of theoretical deconstruction of gender categories" (Barrett 2017: 39).

Even if the art of drag has recently gained popularity among wider public, historically it has its roots in the phenomenon of cross-dressing, which has existed as long as society's expectations towards appropriate clothing for either gender. Traces of this can be found in literature, mythology and theatre all over the world. It can be found in Norse mythology where in one of the eddaic poems, Thrymskvida, Thor is dressed as the bride, pretending to be Freyja, and Loki as the bridesmaid. We can also find cross-dressing in well-known figures such as Hua Mulan - the central protagonist of the Chinese Ballad of Mulan, who pretends to be a man so that she can join the army instead of her aged father, a French heroine of the Hundred Years' War, Joan of Arc, or legendary Pope Joan, who allegedly was a woman pretending to be a man and reigned as pope in the Middle Ages.

Naturally, cross-dressing was a phenomenon that did not only concern historical or fictional figures in the past. In Renaissance England women were not allowed to perform in the theatre, which is why in Shakespeare's plays female parts were performed by cross-dressed men or boys. The same was true of the theatre in ancient Greece. On the other hand, in a classical Japanese kabuki theatre women played both male and female parts (which in fact later transformed into all-male troupes). Cross-dressing was also a part of religious practices, e.g. Korean shamanism or ancient ceremonies of Native Americans, whereas in the Bible it is regarded as an abomination (cf. Deuteronomy 22:5). The abovelisted examples of performances related to drag are only few out of many.

Nowadays, during their performances, drag queens lip sync (i.e. use lip synchronisation); they perform pre-recorded songs of female vocalists to which they dance and move their lips as if they were singing. In addition, they are also stand-up comedians. A particular role enacted on stage can often be an impersonation of a well-known singer or an actress, but quite often drag queens create their unique drag persona. Although make-up, clothing and a wig, play an essential role in creating a particular character, it is not the characterisation that should make the public laugh. Drag queens are comedians who base their comedy on the use of language, and not just on unpolished appearance. In fact, any visual traits of masculinity are considered to indicate the performer's lack of professionalism, but as Barrett says, "[a] primary goal of a drag performance is to highlight mismatches between the performer's 'perceived' identity (as a woman) and her 'biographical' identity (as a man)" (Barrett 1998: 140). What is supposed 
to produce laughter is the disharmony between the produced identities. It is noteworthy that with their extremely high heels, extravagant outfits and make up, drag queens do not produce images of real women but rather a kind of caricature, where features considered as female are purposely exaggerated. The same can be said about their use of language. The speech of drag queens represents the stereotypical perception of the women's way of speaking, which is far from natural feminine discourse.

Nevertheless, the fact that drag performances have their own philosophy does not mean that they are not misogynistic at times. However, when it happens, it is not because drag queens themselves are sexist, but rather because they present the heteronormative ideals of feminine gender performances. Through their clothing, make-up, wigs, and body language, they make reference to such ideals. Significantly, what makes drag such an appealing topic for analysis and discussion is the variety of reactions that it incites and of their ways of its interpretation - from the manifestation of prejudice towards women to the tool of liberation from assigned gender roles. Drag gains importance thanks to the audience who can witness the confrontation between what they feel and know about being a woman or a man, and what they experience during the performance.

\section{The meaning of drag performance}

At present, drag culture is more popular than it has ever been, with drag queens becoming celebrities recognised all over the world. Nonetheless, it has not always been perceived this way. Formerly, and even just a few decades ago, drag was only practiced in underground clubs and bars, even if the related phenomenon of cross-dressing had been present in many cultures for centuries under a slightly different form.

Drag is not simply about men wearing clothes associated with female gender or vice versa. The end of $17^{\text {th }}$ century was the time when female impersonating attained its comedy role (Baker 1994). According to Norton (2016), the very first documented manifestations of drag, similar to the one known today, date back to early 1700s. Performances took place in so-called molly-houses, which was a name for meeting places of homosexual men in $18^{\text {th }}$ and $19^{\text {th }}$ century England and, as homosexual activity was at the time prohibited and consistently prosecuted, most of the information about first drag queens was gathered through infiltration and raids organised on those places (Norton 2016). In $19^{\text {th }}$ century, drag was a prevalent part of theatre culture but in the beginnings of $20^{\text {th }}$ century it started to take a more independent role as performers started to create caricatured female characters (Baker 1994). First mentions concerning gay female impersonators in the literature of the United States come as well from the early $20^{\text {th }}$ century and happen at masquerade balls that took place in New York City (Chauncey 1994). It was also in the early 1930s that several instances of "public disturbances" 
involving female impersonators parading through the streets were recorded (Chauncey 1994).

The phenomenon of drag queens as we know it today could not really emerge until the 1920s or 1930s. It is inseparably connected to the gay community and not until that time had one talked about "the third sex", which was defined as a feminine man or a masculine woman who desired members of the same sex; and that is when drag was linked with homosexuality. This was also the time when drag queens started to be distinguished from other female impersonators. They started performing for homosexual audiences in night clubs and bars, such as San Francisco's Black Cat, where José Serra performed in the 1950s, and the performers stayed at such places until the late $20^{\text {th }}$ century.

The period between the late 1980s and 1990s was an exceptional era for drag during which it began to become a discernible part of art and mainstream culture, with drag queens appearing on TV shows and films, and producing their music. They were amassing large followings with some of them even becoming drag icons known until today, such as Lady Bunny, Pepper LaBeija, or RuPaul.

Even if nowadays homosexuality in the Western world is not something for which you can be arrested or sentenced to death, members of LGBT community still are not granted all civil and political rights. They protest against e.g. violence and employment discrimination related to sexual orientation or gender identity, and fight for the right for a gay couple to get married and adopt children. On the front lines of LGBT activism one has often seen the confrontational art of drag. Drag queens marked their presence during the most renowned LGBT community uprising, the Stonewall riots in New York in 1969 (Carter 2005; Duberman 1993). They have been using their prominent community status to fight for equality. Nevertheless, not all drag queens are engaged activists. For some performers drag is only an entertainment and they do not get involved in political campaigning.

For those who do engage in political actions, new platforms have given other possibilities to use their voice and raise public awareness. Television and other media platforms let drag queens truly be global stars and now have the power to exert influence they did not have before. The social and political changes have in turn influenced the transformation of the art of drag.

All this does not mean that underground drag has vanished entirely. On the contrary, it continues to live its own life. A lot more happens in drag culture than mass media show. Many new styles in drag emerge, including experimental and extravagant forms. One group being in the shadow are "drag kings", that is women playing male roles. Even if less popular, they are continually carving out their own space in drag culture.

The focus of the present paper is on Western drag queen phenomenon, but drag queens can be found in regions where gay individuals still face significant social or legal persecution. As cultural context differs across different times and places, the nature of drag located in other places may also be different from the one described in the paper and focused on the figure of Panti Bliss. 
Panti Bliss is one of the most known drag performers in the world and has gained her ${ }^{1}$ popularity not through appearing on television or social media but because she speaks her mind openly about even the most uncomfortable problems from which, in her opinion, society suffers. She has actively fought for what she believes is right through political campaigning. The following section provides a brief account of the character of Panti Bliss and her diverse activities as a performer and an activist.

\section{Panti Bliss}

Panti Bliss is a drag queen who is now known for being the face of Ireland's marriage equality campaign. Some people would even claim that she helped rewrite the Irish constitution. The real name behind Panti Bliss is Rory O'Neill, an art college student who developed the character in his early twenties.

He became known outside the LGBT communities and theatre scenes much later, in 2014, after appearing on RTÉ Saturday Night Show when a Catholic lobby group, the Iona Institute, and two prominent Irish journalists threatened him with legal action. Eventually, the broadcaster issued a public apology and paid a compensation for defamation. The scandal turned into a national debate on homophobia and the freedom of speech. One of the texts analysed in the present paper is a speech delivered by Panti three weeks later. She spoke in the Abbey Theatre after a play entitled "Risen People" and set in 1913 in Dublin during a mass strike; the main theme of the drama was oppression. Rory claimed that he did not expect anything from it and it was supposed to be "just another speech" for him. However, the speech was recorded by Conor Horgan, an Irish director, who posted the video on YouTube. The recording has received significant interest and provoked national and international debates about homophobia, same-sex partnership and marriage.

Panti's artistic activity had started long before this event. She took part in events organized to raise awareness and funds for people affected by HIV/AIDS, gave performances in both gay bars and more mainstream theatre productions, some of which were staged outside of Ireland, e.g. in Australia, France, the UK, and the USA. Nevertheless, it was the aforementioned appearance at Dublin's Abbey Theatre that gave her international recognisability. It proved to be extremely helpful during the Yes campaign, which led to the legalisation of samesex marriages in Ireland.

In recognition of his political activity, in 2014 Rory O'Neill received the Irish People of the Year award for his contribution to Irish society. He is also a winner of the Gay and Lesbian Award 2009 for Business Person of the Year and the James Joyce Award. In addition, he received an Honorary Degree from Trinity College Dublin. In 2014 Panti's autobiography, Woman in the Making: A memoir was

\footnotetext{
${ }^{1}$ In this paper the feminine forms are used for drag queens in contexts related to their performances and the masculine forms in contexts where their political roles as activists are foregrounded.
} 
published and just one year later, in 2015, a documentary film entitled The Queen of Ireland was released. The film focuses on Rory and the referendum on marriage equality.

The presented paper focuses on two speeches by Panti Bliss. In one of them, the speech given in the Abbey Theatre in Dublin on 1 February 2014 after the aforementioned theatre play, Panti made references to the interview on RTÉ's Saturday Night Show.

The other speech was given on 13 September 2014 during TEDxDublin. On that occasion Panti shared her experience of the little, everyday things that could have significant impact on the wellbeing of homosexual people. For instance, she claimed that even a small gesture of holding hands with your partner could become a political statement when done by people of the same sex. When giving this speech, Panti was already a recognisable figure in Ireland. Her speech gave another reason for discussion on the rights of the LGBT people. In between the two performances, Panti actively campaigned on behalf of Irish gay people for their right to get married, and for promoting social changes. The chosen speeches are two most widely-discussed speeches by Panti given before the referendum and it is believed that the speeches had an impact on its final result.

The analysis considers selected sociolinguistic issues, including how Panti Bliss, or rather Rory O'Neill, creates his image on stage and how he presents the social issues that he wants to promote interweaving the social and the political. The speeches are discussed through the prism of both Rory being a drag performer and a gay right activist. The following chapters discuss the characteristics of both types of discourse.

\section{Language and identity}

Interaction is a way to symbolically communicate shared meaning and identity. It is a process that serves as a means of creating space for individualised group expression through encoding and decoding symbolic meanings (Stryker 1980). Stryker (1980) contends that identity consists not only of who or what one is, but also of meanings and traits attached to an individual by oneself or by others, roles people play during their lives, e.g. in schools, family, or at their workplace.

It is common knowledge that people tend to have expectations that certain individuals play certain roles, but the relationship between context and expectations is not always clear. A person's identity is partially relational, which means that, when exploring it, it is not enough to try and answer "Who am I?," but it may be equally important to elucidate: "Who am I in relation to others?".

When people use language, they do so as individuals with social histories. They partly depend on one's membership in a set of social groups into which they are born. The set of identities given at birth is complemented with another set of identities that come from the memberships developed through the involvement in a range of social activities. However, during a communicative interaction, 
participants are mostly unaware of linguistic variables that create their image. The most powerful factor, in fact, is not who an individual is but how he or she perceives himself or herself through the prism of the expectations of what he or she can or cannot do as a member of various groups, built in the course of time through the process of socialisation. The individual carries similar expectations towards other members of his or her groups. When interacting with others, person's identities become associated with particular range of linguistic actions for realising the desired activities, which are, at the same time, influenced by one's attitudes and beliefs. Communication is therefore in such a perspective a process of mediating a person's image through individual uses and evaluations of linguistic actions.

Goffman (1959) posits that the process of socialisation is a way of learning how to play assigned roles and negotiate a desired impression on a stage, which is what he calls everyday life. The performance is not only a recreation, but also a creation of a speaker's identity. Every individual tries to control the image projected while being in company. Goffman's dramaturgical model sees people as performers and world as a stage in which the setting also influences human behaviour. He divides it into front, back and outside the stage and the place in which an individual finds himself, or herself, influences his or her behaviour (Goffman 1959).

In studying drag queens' identity creation inter alia through the use of language, the concepts described by Goffman appear to be of special relevance. During their performance drag queens make an attempt to persuade others and make them accept their definition of the situation, which is often in contrast to the perception of the situation that the audience have, when confronted with an image of a man cross-dressed and trying to speak as if he was a woman.

Individuals perform identities and, depending on how they understand their social roles and relationships to others, they mediate their engagement and the engagement of others in their socio-culturally important activities. Their patterns of behaviour can be motivated by various reasons, depending on what kind of outcomes they expect to obtain, or what impression they desire to give. The analysis presented in this article aims to uncover which of the speaker's identities are most prevalent in the speeches and what are the reasons for making particular choices. Two types of discourse are in focus, i.e. political discourse and discourse of drag queens, because, as has been pointed out above, drag queens, such as Panti Bliss, are people who emphasise both their social role as a drag queen and a social and political activist.

\section{Language in drag performances}

The groups to which people belong are a vital source of pride and self-esteem and give them a sense of social identity (Tajfel and Turner 1979). According to Barnlund (1988), "every culture attempts to create a universe of discourse for its 
members, a way in which people can interpret their experience and convey it to one another" (Barnlund 1988: 11). Drag queens, as many other marginalised groups, have their unique ways of speaking. Evidently, it has become one of the ways in which the community members can distinct themselves from people outside the community and also make connections with other members of the group.

One of the most characteristic elements of their discourse is speaking "like a woman" even if biologically they are men. Significantly, Butler (1990) also argues that the presentation of the gendered self is performative via physical and sartorial messages and via particular ways of using language; for her drag queens' discourse is a good illustration of the phenomenon. The "femininity" of drag queens' discourse is but one of its many characteristic features. As it has been mentioned drag queens base their comedy on the use of language.

As blurring (and in another way emphasising) the differences between genders is one of the issues about which drag is concerned, expressing one's gender in a well-designed way is one of the first characteristics of drag performances. It stays in line with Butler's (1990) claim that gender is always performative, and feminine or masculine behaviour, together with expectations towards each of the sexes, are purely social constructs and not something that is given to people at birth together with their biological sex.

The definition of gender can quite naturally be found in language, which is a powerful factor in creating one's identity. As early as 1975, Lakoff coined the notion of women's language, when she compared language use between men and women and presented her conclusion that women's language possesses a set of characteristics, such as e.g. hypercorrect grammar, extended vocabulary, the knowledge concerning typical woman's work (e.g. references to sewing, use of precise colour terms) or using a higher number of expressives (i.e. phrases related to emotion and inner feelings) or backchannel utterances (e.g. "oh", "wow"), and tag questions (Lakoff 1975). Women's language is in fact based on the stereotypical image of a white middle-class woman living in the Anglo-Saxon, Anglo-American world. It is rather a description of stereotypical perception of feminine speech, and it may not be the best description of how women speak today in the real world.

Ochs (1992) agrees that the notion of gender is based on the distinction between biological sexes projected onto sociocultural context. In other words, men and women are perceived in a different way in society and they are attributed different roles. As language is one of the major streams to channel identity, ideologically it is also expected to be influenced by one's gender. For Ochs, there is a small number of linguistic characteristics that directly and exclusively index gender. The speech of a drag queen represents the stereotypical perception of how "a woman" speaks, and so is for her behaviour on stage.

It is noteworthy that in his study Barrett $(1998,1999)$ refers to Lakoff's characteristics of women's language, which in his opinion is a strong symbol of some idealised femininity, and thus a powerful tool for performing female identity. Some of the elements discussed by Lakoff can be found in drag queens 
speech, but not all of them. For instance, drag queens are entertainers, so they do tell jokes. As Barrett (2017) points out "several of these, such as the use of precise colour terms, empty adjectives, and intensive "so", overlap with stereotypes of gay male speech" (Barrett 2017: 47). However, empty adjectives that are classified as typically gay are characteristic of this social group (e.g. lexems such as "flawless", "fierce", "fabulous") in opposition to empty adjectives originally listed by Lakoff, which are more connected to the white-woman style of speaking.

Naturally, it is not only gender that is expressed through language use. Sociolinguistic studies have departed from the assumption that there is a one-toone relationship between language use and membership in some identity group. Drag queens are a perfect example of speakers who demonstrate their interconnected identities, related to gender, class, and ethnicity, through language, and through variety introduced into their discourse; during a show, white woman's speech is interwoven into texture where styles presenting different gender and racial belonging are also present.

This kind of "mixing" styles can be found in other settings. With regard to gay identity, for instance, Barrett (1999) presents an analysis of performances of professional drag entertainers in gay bars. In such contexts, the main goal of the performer is to make the audience laugh through projecting a fictional identity of a white, heterosexual, upper-class woman through stylistic choices adequate to what Lakoff (1975) describes as women's language. The speech style is interrupted by using markers that "reveal" the fact that the performer is really an African American gay man.

Barrett (1998) also provides a discussion of the performances of American drag queens, through which they reflect their racial identity through the usage of African American English, where performers include certain markers in their speech to emphasise that biologically they are male African Americans. As drag queens are considered a subcategory of gay men community, one will also find traits of the gay male style of speaking in their discourse (Barrett 2017). One typical example is their use of the above-mentioned characteristic adjectives, viz. "flawless", "fierce", and "fabulous", or intensive use of "so".

What is also noteworthy is drag queens' interesting lexical choices. The performed analysis of drag queens' discourse has shown that one can distinguish many lexemes that acquire non-standard meaning, different from their semantics when they are used outside the community. For example, "to gag" in drag discourse will often mean "to react intensely, usually as a result of a positive shock", the word "sickening" can be used to complement someone's appearance as it will mean that they look "so amazing that it makes you physically sick", "reading" is a term for exposing a person's flaws wittily and incisively, "throwing shade" is the act of rather blunt and insulting criticism, "tea" will often be connected with "truth" and gossip (Szymańska 2018). Thus, "spill the tea/give the tea" is in drag discourse naturally interpreted as revealing secrets, gossiping. There are also expressions that refer specifically to the phenomena present in the art of drag, e.g. "beat a face" means to apply a perfect amount of makeup and 
"tucking" is used to refer to placing genitals between legs so that they are not visible from the front.

What is also characteristic for drag queens is referring to their social group as "drag family". During interactions, drag queens often address one another as "sister," and they use the term "drag mother" for their mentor. Such linguistic choices reflect the genuine feel of belonging to the group (Szymańska 2018).

Interestingly, some of the vocabulary items which use had been considered exclusive for the drag communit,y have gradually emancipated and can be found now in everyday language, i.e. the language at large not limited to the drag community. The words and phrases such as listed above will now often be used by people who do not identify themselves with any members of LGBT community. This phenomenon may be treated as a proof that drag has found its place in popular culture.

Apart from marking the belonging to the drag queen community and adding an extra artistic and comic value to the performances, drag queens use their special discourse for yet another purpose. It is through language that they are able to emphasise that they are blurring boundaries between genders, and that they are not just the identity that the outfit they wear could suggest. Language has turned drag into a statement thanks to which the outfit can send a message itself. It is also language that has been helping fight against misconceptions and oppression, spreading the ideology that they share as a group. As a minority group, drag queens often have to defend their style of living and as gay people at many places they still need to struggle to receive treatment equal with that of the rest of society.

\section{Language and politics}

Politics and language naturally go together. Van Dijk (2005) points out that ideologies are purveyed to members of a group or a culture through complex processes of socialisation and that the ideologies are acquired progressively. $\mathrm{He}$ recognises the importance of discourse in the construction and reproduction of ideologies, as language shows the mental representation of ideology among other means (Van Dijk 1998).

As mentioned above, any individual adjusts his or her identity accordingly to the situation or environment he or she finds him- or herself in, and at the same time expresses the ideology that at the moment seems more relevant to the situation. Also, the individual can adjust his or her ideology in order to manage conflict of beliefs or interest, for example when one's point of view can put him or her in an inconvenient position (Van Dijk 1998).

It seems that the lack of acceptance and comprehension on the part of the wider society, which drag queens had to face, enforced them to become politically active. Many drag queens are activists fighting for equal rights for the members of their community. For this reason, it is not unusual that they include political messages in their performances. As a result, the performance will naturally be 
more than pure entertainment; it will often have an educative and a persuasive purpose just as other political speeches do. Panti Bliss serves as a good example in this context. Panti does not only consider herself to be a drag queen, but also positions herself (and himself) as a gay right activist (or rather an "accidental activist" as she labels herself). The two speeches whose analysis is included in the present paper were part of the political campaign in which Panti Bliss actively took part, and of which she was the spokesperson, fighting for legal marriage equality for homosexual couples in Ireland. Thus, it is not possible to discuss Panti Bliss's performances and discourse disregarding the political dimension.

The role of Panti Bliss as a public figure can be better seen in the light of political and philosophical ideas. According to the philosopher A. J. Ayer (1936), absolute truth does not exist; instead truth is relative and subjective. It means that "a truth" is an assertion of an individual in which the particular individual believes. Such relativity of truth is based on an ideological view of the individual and is reflected in the way he or she uses language to describe events or comment on them. Language thus is a means of communication and presents the individual's point of view; it is also a tool shaping other people's beliefs and influencing their opinions. What is more, the ideological position of the hearers plays a role in the way they respond to an utterance.

In order to describe and analyse any type of discourse it is useful to ask for what purposes it is used. As for political discourse, the main aim of a speaker will often be to persuade listeners to accept his or her vision of the world and his or her opinions; at the same time the speaker needs to appear as a trustworthy and reasonable person. To achieve this, the speaker can use rhetorical devices and engage in "the art of persuasive discourse" (cf. Beard 2000: 35), where the word "discourse" refers to both spoken and written language. In this richly Aristotelian perspective rhetoric is the "art of persuasion" and an important part of human activity. Plato, per contra, sees rhetoric primarily as a tool for manipulation to be used by people with insincere intentions. Despite the differences between Aristotle's and Plato's opinion on the role of rhetoric (cf. discussion in Beard 2000), they both agree that the skills of rhetoric can be found in all human communication, but they are especially visible in political contexts.

There are several common strategies of persuasion in political speeches that are used to impose certain moral or ethical values and they may include a tactical employment of such linguistic elements as, inter alia, metaphors, repetitions, contrastive pairs, presuppositions, implicature, and personal pronouns.

Metaphor is relevant in political discourse, especially when approached not as a simply ornamental figure of speech characteristic of literary language, but, rather, as an indispensable element of language which can be used and abused. As shown by Lakoff and Johnson already in 1980, metaphor does not have to be alienated from reality and from colloquial language; it is an expressive literary agent found in a wide variety of fields, such as economical, legal, scientific, or political discourses, where metaphor may be used to serve different rhetorical purposes (cf. e.g. Wojtczak et al. 2017). The analysis of speakers' choices of metaphors to describe phenomena and situations can reflect their attitudes towards 
them but can also guide the audience towards a vision of world phenomena preferred by the creator of the message. The metaphors used by politicians often tend to influence the audience, but at the same time exert an emotional impact on the recipients of the message (Ungerer and Schmid 2006).

Another strategy which can enhance the persuasive impact of a particular message is repetition. As Jones and Wareing point out "repeating certain phrases contributes towards making the ideas contained in them seem "common sense"" (Jones and Wareing 1999: 39). Beard (2000) argues that in long speeches the role of repetition is typically twofold: to emphasise moral values presented by the speaker and to hold the long speech together. There is one particular type of repetition that has been discussed at length by researchers - the three-part list (Beard 2000). Charteris-Black (2005) characterises the roles of the three 'chunks' as follows: the first part is the initiation of an argument, the second part emphasises or responds to the first, and the third, i.e. the last part reinforces the previous two and also marks that the argument has been completed, making the text more coherent and cohesive, as well as more memorable.

When two ideas are presented in the speech, the difference between them can be indicated through contrasts or antithesis. The contrast can be built between, for example, "now" and "then", or "us" and "them", creating "contrastive pairs" in relevant discourse. Politicians can use contrastive pairs to talk, for example, about positive and negative aspects of an idea, compare the past with the present or the present with the future. It is also a device used to highlight the positive aspects of the speaker's way of thinking contrasted with "the other" points of view. As will be seen in further section of the paper, Panti Bliss successfully uses the strategy of contrastive pairs to promote the idea of the legalisation of same-sex marriage, showing the opponents as irrational and prejudiced.

Implicatures and presuppositions, being types of suggested meaning, which naturally save the sender of the message from direct responsibility for the communicated content, are also frequently used in persuasive discourse. Pragmatic presupposition understood as shared, background knowledge, or information positioned as such (cf. Stalnaker 1974), can be used strategically, e.g. to make the audience believe that something is, has been, or was, the case. In turn, employing implicatures, i.e. creating meanings beyond words, will allow the speaker to create understatements and innuendos, which can prove particularly useful, especially when discussing a controversial topic, making empty promises, etc. Implicature can add value to a speech creating and exposing messages to which the speaker does not have to be committed. Both presupposition and implicature can serve persuasive aims when what is implicated or (especially) presupposed concerns values, ideals or social norms. For instance, using presupposition helps avoiding assertion on certain topics, which may entail a further discussion or be questioned. However, even when using suggested meanings, such as presuppositions, the speaker needs to win his or her audience's approval of the presented view on an aspect (Sbisà 1999).

The relevance of the rhetorical devices listed above in the context of Panti Bliss's discourse will be shown in the next section in the analysis of her two 
speeches which concern homophobia in society. The analysis shows the complexity of the drag queen's speeches which combine entertainment with political and social campaigning.

\section{Analysis of two speeches by Panti Bliss}

Panti Bliss is an actor, the most popular Irish drag queen and a gay right activist. The two speeches analysed here were give before the Irish referendum on 22 May 2015 concerning same-sex marriage. It is believed that the speeches had exerted significant impact and contributed to shaping public opinion, which at least partly, led to the introduction of the 34th Amendment of the Constitution of Ireland legalising same-sex marriage. This made Ireland the first country to legalise samesex marriage by popular vote.

The fact that Panti's speeches involve different dimensions, and that the performer has a multifaceted career, as an actor, an activist, and a drag queen, requires a complex research apparatus, which will embrace the performance both in terms of visual, dynamic acting and linguistic action. In drag queens' performances what influences the audience is the overall impression coming from the interplay of the visual and the linguistic.

As the speeches are given while Rory O'Neill assumes the role of Panti Bliss, in the analysis (as in the whole text) the female pronouns are employed to talk about the speaker.

\subsection{Drag performances: the role of the appearance}

It is noteworthy that both analysed speeches were given when the speaker was in drag. The drag queen's appearance evidently influences the entire reception of the performance and sets the tone for the speeches. First of all, as already mentioned above, the outfit has a meaning itself and sends a message during the act. Second, when the speaker, who is an adult male, appears in front of the audience in a wig and a dress, and is wearing fake lashes and lipstick, it can cause shock, amusement, or excite curiosity with regard to the aim of the act itself; it will also attract attention. It is not insignificant either that the image presented by the speaker is contrasted with the topic of the speech. Seeing such a figure, the audience may think that this is going to be (just) a drag performance, or simply a joke, and may not be aware of the gravity of the issues that the speaker is planning to address.

Therefore, eventually, it is not only the language that conveys the message; appearance does it as well. It puts forward the idea that reality is not given but created. As in Ayer's (1936) theory, there is not one and ideal objective truth, and sometimes it is worth to question the things that we think we know. It is a vital argument when it comes to changing other people's minds; first we need them to want to listen to us and to take our arguments into consideration. 
Thus, the identity of the speaker plays a fundamental role in the speeches. She (i.e. Panti) is a representative of a certain group: the group to which she belongs and for which rights she fights. It can happen that for many people in the audience she is the first drag queen they have ever seen, or maybe even the first LGBT community representative that has ever addressed them. That is why the way in which the speaker presents herself may influence, or create, the perception of her entire community.

Another aspect of appearing on stage in drag may be related to Goffman's ideas concerning public and private face. The art of drag can be perceived as a literal representation of the person's public face, which in the case of drag queens is their drag persona. In this perspective Rory O'Neill makes Panti Bliss a spokesperson for his views and opinions. It is usually Panti, not Rory, who fights for the rights of LGBT people, appears on posters, gives interviews and speeches. It can be said that in the context of the campaign, the figure of Panti has become the front stage creation of Rory.

\subsection{Drag performance: the role of words}

Both of the speeches open with a joke, which is a typical feature of drag performances. Telling jokes can also be a strategy used by politicians. However, in Panti Bliss's opening jokes in the speech at Abbey Theatre (1) and during TEDxDublin (2), she makes fun of herself, which is usually avoided in political speeches where politicians struggle to save their (public) face.

(1) Hello. My name is Panti and for the benefit of the visually impaired or the incredibly naïve I am a drag queen, I'm also I guess a performer of sorts, and an accidental and occasional gay rights activist. And as you may have already gathered, I am also painfully middleclass.

(2) I am 45 years old - I know, I look amazing. Thank you.

In drag performances jokes seem to be a strategy and starting with a joke is a strategy to win the audience at the very beginning of a performance. Other jokes, which appear throughout the speeches also seem to build a rapport with the audience, e.g.:

(3) gay people are just as capable of bringing goodness into Mary's life as anybody else. And, of course, we could help her with the decorating.

(4) Of course, many people object to the word "homophobia" itself. They object to the "phobia" part. "I'm not afraid of you", they say. But I'm not saying homophobes cower in fear every time they pass a Cher album

Apart from winning the audience through ridiculing the speaker, the jokes also ridicule the arguments against the speaker's point of view (5). The jokes are strategically worked into the speeches, creating a balanced combination of humour and seriousness, which helps to convey the message. Thus, the speaker 
opens the speech in a humorous way, but later the speech takes on a serious tone which is introduced with an emphasis (6), which is repeated later on in the speech several times.

(5) These days you'll find those very vocal homophobes clustered around the same sex marriage debate, and it is quite the spectacle. (...) They are forced to sort of scramble for any other reason that they can think of to argue their case; so "gay people are going to destroy the institution of marriage", "gay couples will be wandering through orphanages picking babies off shelves trying to find one that matches their new Ikea sofa".

(6) But I do know a little something about oppression. Oppression is something I can relate to. Now, I'm not of course for a minute going to compare my situation to Dublin workers of 1913 but I do know what it feels like to be put in your place.

The first lines, where she discusses her social status, also set the scene. The speaker presents herself, in an amusing manner, which can be a way to gain the audience's trust through getting them to know something about her life. In the introduction, she talks about herself using certain labels, such as "drag queen", "performer", "gay rights activist", "middle-class". For the duration of the speech she does not abandon one role for another, but wants to be seen through the prism of all of them at the same time. Throughout the speech, Panti marks not only her identity as a drag queen or an activist, but also a set of other identities, such as social class and status, or sexual orientation. Giving the information about her social status, education and family is done with an intention of showing that she is as many other people, even if on the surface it may not appear so. The message "I am [we, gay people, are] just like you" is one of the key concepts that are presented throughout both of the speeches. It is not only stated indirectly but also directly in the end of the second speech (7).

(7) Despite appearances, I am just as ordinary, just as unremarkable, and just as human as you are.

It should not come as a surprise that she employs such a strategy as the aim of the speaker is to convince the audience that she deserves the same right as straight people, thus, she aims at blurring the differences. What she wants to achieve is to show that marriages between two people of the same sex are as natural as the "traditional" ones.

In the first speech, Panti calls herself an "accidental activist" and mentions that she "always managed to find gainful employment" in the field of "gender discombobulation". Those two expressions have become slogans that have been repeated in the press articles commenting on the speech evidently due to the fact that they attract attention and are memorable. Apart from the humorous side, the phrase "accidental activist" includes alliteration, which also makes it easy to retain in memory. The phrase has a humorous tone, thanks to which it can be easier for more suspicious members of the audience to let their guard down and accept the speakers's upcoming arguments. The informal and playful character of the word "discombobulation" can make those who are not comfortable with the subject of 
gender fluidity feel more at ease. It can be treated as a sign that the performance is not supposed to be a lecture during which the speaker is going to attack someone, assign guilt, or impose her point of view on whoever happens to be around.

Panti Bliss plays with personal pronouns and employs them in such a way that they work to her advantage. In the first speech, she brings up selected examples illustrative of the situations she has experienced, which she labels as "oppressive". Whilst the employment of this adjective, which becomes a reference point of the speech, is discussed later in the analysis, another noticeable strategy appears here - she switches from the first singular person pronoun "I" to the second person pronoun "you" (8), (9). This manoeuvre can emphasise the blurring of the differences between the speaker and the audience, and, at the same time, creates the opportunity for the audience to put aside their point of view and try to see things from the speaker's position.

(8) They are all sitting around and they are having a reasoned debate on the television, a reasoned debate about you. About what kind of a person you are, about whether you are capable of being a good parent, about whether you want to destroy marriage, about whether you are safe around children, about whether God herself thinks you are an abomination, about whether in fact you are "intrinsically disordered".

(9) And anyway, then you sort of think 'well we've had such a lovely afternoon poking around in that garden centre looking at things for the garden we don't actually have' and then you think 'all it will take is one spat "faggots" or a split lip' to turn that really lovely afternoon into a bad afternoon that you will never want to remember.

There are moments, however, where the speaker abandons the strategy of integration and emphasises the differences between her and the audience instead. She appears to assume that most of the people are not homosexual, and that it is straight people at whom these speeches are aimed. The message seems to be that it is straight people that need to be convinced to see things her way; thus, next to the arguments showing that people ("we") are all the same, the speaker also shows that "we" are different because gay people do not have the same rights and are treated differently by society, e.g.:

(10) But we stroll on hand-in-hand trying to be just normal and carefree, just like everybody else; but actually we're not because we are constantly scanning the pavement ahead, you know, just in case.

She creates two groups which she labels as "straight people" and "gay people/LGBT people," and also uses the first person plural pronoun "we" to mark her belonging to the latter group. The speaker, however, points out that even if there exist differences between heterosexuals and homosexuals, once again, (inclusively) "we" are all the same.

A certain pattern is visible in both speeches. The speaker creates a number of images through storytelling, giving some examples from her life. In the first 
speech, the examples given by the speaker all open with the expression "Have you ever..." and close by the repetition of the sentence "And that feels oppressive". In the second speech, the examples open with the expression "I (will) see" and close with "And I am jealous...". These repetitive patterns give a frame to each speech. The words are repeated like a chorus in a song. The speaker not only introduces highlighted ideas, but also gets back to them later, as she does, for example, with the story about being assaulted by a group of men when standing at a pedestrian crossing in the first speech. It also appears in the second speech as the motive of holding hands with the speaker's partner. The repetitions, and the framing strategy makes the speeches more cohesive and coherent. Repetitions are also a rhetorical strategy and can enhance persuasion. They appear throughout the speeches, and although they do not necessarily appear in groups of three, they do fulfill the functions described by Beard (2000).

The speaker supports her arguments by giving examples of normal everyday situations which should have been familiar to most of the people in the audience. However, what appears to be a departure from "normal" is the feelings that evidently accompany the speaker when she narrates the situations. This is Panti Bliss's way to shows the difficulty, or "abnormality," of everyday life of homosexual people. Talking about everyday life situations like holding hands with a partner in a department store, crossing the street, being in a train with a friend or reading paper in a neighbourhood café make the discussed problems more concrete and noticeable. Combining this with her established argument that heterosexuals and homosexuals are not different from each other, it creates the feeling of injustice. It is enhanced by the repetitive use of the second personal pronoun and by the phrasal repetitions.

The opening lines of the second speech (3) are supposed to show abnormality of the described situation with a presupposition that when you are forty-five you should have done such a thing in your life already, and that this is caused by the faulty system that needs to be changed.

(11) I am 45 years old - I know, I look amazing. Thank you. I am 45 years old, and I have never once unselfconsciously held hands with a lover in public. I am 45 years old, and I have never once casually, comfortably, carelessly held hands with a partner in public.

The speaker does not state directly in this fragment that she is against this state of affairs. First, she lets the audience to come to this conclusion before she comments on it. She continues with this strategy when telling other stories and then returns to the motive of holding hands and here directly points out to the problem.

Another rhetorical device used by the speaker are metaphors. For example, the speaker talks about her mental state in terms of physical state. She says that it "hurts" when she is being insulted, that the society is "stiflingly" homophobic, and that it is hard to be raised in such a society and remain "unscathed". In the second speech, the use of metaphor together with repetition to present 
homophobia as a liquid with which the society is "infused" and with which it is "dripping" puts stress on scale of the problem (13).

The recurring motive of the speeches is homophobia. The words "homophobe", "homophobia" and "homophobic" appear many times in the texts and usually in a condensed manner (12).

(12) It turns out that gay people are not the victims of homophobia. Homophobes are the victims of homophobia. But I want to say that it is not true. Because I don't hate you. I do, it is true, believe that almost all of you are probably homophobes. But I'm a homophobe.

(13) Our society is homophobic. It is infused with homophobia. It is dripping with homophobia.

The speaker explains what she thinks homophobia really is and says that it is very often misdefined. The repetitions are meant to support her claim. The repetitions play different roles. There are used to introduce an initiation of the idea, the emphasis and the reinforcement (13) or to highlight the absurdity of the described situation (12).

The speaker also incorporates the image of the opposition - people who disagree with her on the matter of the marriage rights for homosexual couples or other who do not feel comfortable with her lifestyle. As it has already been mentioned, she labels these behaviours as "oppressive". She also evokes examples of insults that came from them towards her or instances of aggressive behaviour.

What is more, she makes a list of arguments supposedly made by those who oppose the same-sex marriages (14). The given arguments, which are presented as if they were directly cited, sound irrational and make the opposition appear ridiculous. The use of irony emphasises the effect. She continues by giving other example, which she thinks is "the real driver of homophobia" in the same preposterous way. In addition, she uses irony when addressing the changes that the legalisation would entail and she states explicitly that the fears are "irrational" (15).

(14) They are forced to sort of scramble for any other reason that they can think of to argue their case; so "gay people are going to destroy the institution of marriage", "gay couples will be wandering through orphanages picking babies off shelves trying to find one that matches their new Ikea sofa", or that "allowing gay people to get married will destroy society itself", and many many more. Including my own personal favourite which is the old argument that "the word "marriage" is defined in some dictionary or other as "the union between a man and a woman" and that therefore same sex marriage can't possibly be a marriage', which is a piffling argument against words and dictionaries and not an argument against same sex marriage.

(15) But, of course, their fear is irrational. Because, of course, the world will not look any different. You know, kids will still want to eat ice cream, dogs will still want to play fetch, the tide will still come in, and parallel parking will still be difficult.

Most of the discussed aspects of the speeches concerned persuasion and strategies to present one's point of view. When looking at the language of the 
speeches there are not many aspects of the drag queens discourse. Apart from the overall appearance, Panti's performances that are discussed here are not typical drag performances. The features that characterise her linguistically as a drag queen are jokes. The speaker also labels herself as "drag queen" and while presenting herself, gives her stage name.

They are not a pure political speech either. Panti implements these two roles and chooses what aspects of her identity she wants to present to the audience. Her linguistic (and non-linguistic) choices are influenced by such factors as who she is, in what situation she finds herself, to whom she speaks, why she does it and what she wants to achieve.

\section{Conclusions}

It can be said that language is one of the most important way of expressing one's identity, or rather a set of identities. In the case of drag queens, even if the entire façade created through dresses, high-heels, makeup, wigs or padding is important, it is the appropriate use of language that is supposed to "give them away" and to show that they are not actually women but drag queens.

The speaker uses the contrast between who she appears to be and who she says she is. It is a play between what we see (thus, what we may think we now) and how things really are. In the speech, Panti presents herself as an ordinary person, not much different from any other people in the audience despite her appearance on the stage.

Clearly, not all of the subject's identities would be shown in one moment. It is so because even though people have multiple, intersecting identities, not all of those identities are relevant in a particular situation. The situation in which Panti is placed predisposes her to speak in a certain way that allows her to communicate the intentions and achieve the goals successfully. She is a drag queen and does not hide this aspect of her identity during the performances.

However, she does not speak purely like one because of the nature of the performances that are the subject of analysis in this paper. The samples for Barrett's (1998) research of the language used by drag queens, which were taken as a point of reference, were gathered from performances in gay bars, thus it is possible to say that the aim was different and so was the target audience of those speeches. The performers aimed at being purely entertaining and funny, and the audience was comprised of people favourable to the topic of gender fluidity.

On the other hand, the speeches analysed in this article were presented in front of a wider public which may have not known what drag was or might have even taken a hostile attitude towards the speaker or the discussed topic. The speaker's objective is not only to entertain the public. Being funny is rather a mean to gain the audience's favour. The objective is to convey the message and to convince the audience.

That is why in the analysed speeches Panti shows herself not only as a drag queen, by keeping the entertaining dimension of the speeches and the appearance 
of a drag queen, but also as a political activist, through employing a set of rhetorical strategies of persuasion into her speeches. Furthermore, she also marks other identities, such as sexual orientation or social class belonging.

The chosen approach shows that it is worth to look at discourse from wider perspective - knowing the speaker and what drives him or her can help to see what has been missing. Sometimes one identity, thus taking into consideration one type of discourse, is not enough to understand the illocutionary force behind it.

\section{References}

Ackroyd, Peter. 1979. Dressing up - Transvestism and drag: The history of an obsession. New York: Simon and Schuster.

Ayer, Alfred Jules. 1936. Language, Truth and Logic. London: Gollancz.

Baker, Roger. 1994. Drag: A history of female impersonation in the performing arts. New York: NYU Press.

Barnlund, Dean C. 1988. Communication in a global village. In L. A. Samovar and R. E. Porter (eds.), Intercultural communication: A reader, 5th ed., 5-14. Belmont: Wadsworth.

Barrett, Rusty. 1998. Markedness and styleswitching in performances by African American drag queens. In C. Myers-Scotton (ed.), Codes and consequences: Choosing linguistic varieties, 139161. New York: Oxford University Press.

Barrett, Rusty. 1999. Indexing polyphonous identity in the speech of African American drag queens. In M. Bucholtz, A. C. Liang and L. L. Sutton (eds.), Reinventing Identities: The Gendered Self in Discourse, 313-331. New York and Oxford: Oxford University Press.

Barrett, Rusty. 2017. From drag queens to leathermen: Language, gender, and gay male subcultures. New York: Oxford University Press. https://doi.org/10.1093/acprof:oso/9780195390179.001.0001

Beard, Adrian. 2000. The Language of Politics. London: Routledge.

Butler, Judith. 1990. Gender trouble: Feminism and the subversion of identity. New York: Routledge.

Butler, Judith. 1993. Bodies that Matter: One the discursive limits of "sex". New York: Routledge.

Carter, David. 2005. Stonewall: The riots that sparked the gay revolution. New York: Macmillan.

Charteris-Black, Jonathan. 2005. Politicians and Rhetoric: The Persuasive Power of Metaphor. Houndmills, Basingstoke, Hampshire, New York: Palgrave Macmillan. https://doi.org/10.1057/9780230501706

Chauncey, George. 1994. Gay New York: Gender, urban culture, and the making of the gay male world, 1890-1940. New York: Basic Books.

Duberman, Martin. 1993. Stonewall. New York: Dutton.

Feinberg, Leslie. 1996. Transgender warriors: Making history from Joan of Arc to RuPaul. Boston: Beacon Press.

Fleisher, Julian. 1996. The Drag Queens of New York, NY: An illustrated field guide. New York: Riverhead Books.

Garber, Marjorie. 1983. Vested interests: Cross- dressing and cultural anxiety. New York: Routledge.

Gilbert, Sandra M. 1980. Costumes of the mind: Transvestism as metaphor in modern literature. Critical Inquiry, 7, 391-417. https://doi.org/10.1086/448105

Goffman, Erving. 1959. The Presentation of Self in Everyday Life. New York: Doubleday.

Greaf, Caitlin. 2016. Drag queens and gender identity. Journal of Gender Studies, 25(6), 655-665. https://doi.org/10.1080/09589236.2015.1087308 
Hilbert, Jeffrey. 1995. The politics of drag. In C. K. Creekmur, and A. Doty (eds.), Out in culture: Gay, lesbian and queer essays on popular culture, 463-469. Durham: Duke University Press. https://doi.org/10.2307/j.ctv1220htt.32

Jones, Jason and Wareing, Shan. 1999. Language and Politics. In L. Thomas, et al. (eds.), Language, Society and Power, 31-47. London: Routledge.

Lakoff, George and Johnson, Mark. 1980. Metaphors we live by. Chicago: University of Chicago Press.

Lakoff, Robin. 1975. Language and woman's place. New York: Harper and Row.

Norton, Rictor. 2016. Myth of the modern homosexual: Queer history and the search for cultural unity. London: Bloomsbury. https://doi.org/10.5040/9781474286916

Ochs, Elinor. 1992. Indexing gender. In A. Duranti (ed.), Rethinking context: Language as an interactive phenomenon, 335-358. Cambridge: Cambridge University Press.

Raymond, Janice. 1994. [1979]. The transsexual empire: The making of the she-male. New York: Teachers College Press.

Raymond, Janice. 1996. The politics of transgenderism. In R. Ekins and D. Kind (eds)., Blending genders: Social aspects of cross- dressing and sex-changing, 215-223. New York: Routledge.

Rupp, Leila. J., Shapiro, Eve Illiana and Taylor, Verta. 2010. Drag queens and drag kings: The difference gender makes. Sexualities, 13, 275-294. https://doi.org/10.1177/1363460709352725

Sbisà, Marina. 1999. Ideology and the persuasive use of presupposition. In J. Verschueren (ed.), Language and ideology. Selected papers from the 6th International Pragmatics Conference, 492-509. Antwerp: International Pragmatics Association.

Showalter, Elaine. 1983. Critical cross-dressing: Male feminists and the woman of the year. Raritan, $3(2), 130-149$.

Stalnaker, Robert. 1974. Pragmatic presuppositions. In M. K. Munitz and P. K. Unger (eds.), Semantics and Philosophy, 197-213. New York: New York University Press.

Stryker, Sheldon. 1980. Symbolic interactionism: A social structural version. Menlo Park: Benjamin Cummings.

Szymańska, Maria. 2018. Dyskurs „drag queens” - kilka refleksji na temat performatywnej roli języka. In I. Witczak-Plisiecka and M. Deckert (eds.), Dyskurs - wspótczesne opracowania $i$ perspektywy badawcze, 127-139. Łódź: Wydawnictwo Uniwersytetu Łódzkiego.

Tajfel, Henri and Turner, John. C. 1979. An integrative theory of intergroup conflict. Organizational identity: A reader, 56-65.

Ungerer, Friedrich and Schmid, Hans-Jorg. 2006. An introduction to cognitive linguistics. London: Routledge.

Van Dijk, Teun Adrianus. 1998. Ideology: A multidisciplinary approach. Trowbridge: Sage.

Van Dijk, Teun Adrianus. 2005. Discourse analysis as ideology analysis. In C. Schäffne and A. L. Wenden (eds.), Language \& peace, 41-58. Singapore: Routledge.

Williamson, Judith. 1986. Consuming passions: The dynamics of popular culture. London: Marion Boyars.

Wojtczak, Sylwia, Witczak-Plisiecka, Iwona and Augustyn Rafał. 2017. Metafory konceptualne jako narzędzia rozumowania i poznania prawniczego. Warsaw: Wolters Kluwer Poland. 